\title{
Socio-economic, dietary, activity, nutrition and body weight transitions in South Korea
}

\author{
Soo-Kyung Lee ${ }^{1, *}$ and Jeffery Sobal ${ }^{2}$ \\ 'Department of Nutritional Sciences, Rutgers, The State University of New Jersey, 26 Nichol Avenue, Davison Hall, \\ New Brunswick, NJ 08901-2882, USA: ${ }^{2}$ Division of Nutritional Sciences, Cornell University, lthaca, NY 19853, USA
}

Submitted 18 February 2003: Accepted 7 May 2003

\begin{abstract}
Objective: Socio-economic development influences many factors that affect health, especially diet and nutrition. This investigation proposes that a system of transitions occur as societies develop, with socio-economic, physical activity, dietary, nutrition and body weight transitions operating in relationship with each other. This model of transitions was examined empirically using South Korea as an example of a nation that has undergone considerable changes.

Design: Data were drawn from published government reports: the Korean National Nutrition Survey and annual reports at the national level for the years between 1969 and 1993. The socio-economic transition was assessed by gross national product. The physical activity transition was assessed using annual proportions of the population involved in primary, secondary and tertiary industries, as well as the number of cars and driver's licences. The dietary transition was measured by plant and animal food consumption. The nutrition transition was assessed by percentages of energy from carbohydrate, protein and fat. The body weight transition was measured by body mass index calculated from the average height and weight of adolescents.

Results: Results revealed that the transitions were highly correlated as expected, with the socio-economic transition exhibiting major changes. South Koreans tended to decrease their physical activity and plant food consumption, and to increase animal food consumption, percentage of energy from dietary fat and body weight, in relationship to the socio-economic transition.

Conclusion: Examining a system of transitions on a national level in one country that has undergone rapid economic development may provide a strategy for examining how such transitions operate in other nations.
\end{abstract}

Keywords
Socio-economic
Dietary
Activity
Nutrition
Weight
Transitions
South Korea

Public health is influenced by interrelationships among many factors in society. Economic development is an important influence on factors that affect health, especially diet and nutrition. This investigation proposes that a system of transitions occur as societies develop, with socio-economic, physical activity, dietary, nutrition and body weight transitions operating in relationship with each other. The proposed system of relationships between these transitions is shown in Fig. 1, where socio-economic transitions influence activity and dietary transitions, which in turn lead to transitions in body weight. Other transitions also occur as part of the system of transitions associated with development, including demographic transitions ${ }^{1}$, mobility transitions ${ }^{2}$, epidemiological transitions ${ }^{3-5}$ and others that will not be considered here in an attempt to focus on public health nutrition issues.

Socio-economic transitions occur as societies undergo social changes during modernisation and economic development ${ }^{6,7}$. As societies industrialise, the relative economic size of agriculture sectors declines, the manufacturing sector increases and the service sector increases $^{8}$. Sectoral changes are reflected in societal shifts in overall economic productivity, individual household incomes and human capital development of the population $^{8}$. The geographic distribution of the population is also affected. The majority of people tend to live in rural areas before economic development; however, more and more congregate in urban areas as economic development proceeds $^{9,10}$.

Physical activity transitions are influenced by socioeconomic transitions. The level of physical activity decreases with the declining proportion of the population involved in agricultural work and the increasing proportion of the population involved in service work $^{11}$. Physical activity transitions lead to less physical energy expenditure on the job ${ }^{12,13}$. The mode 


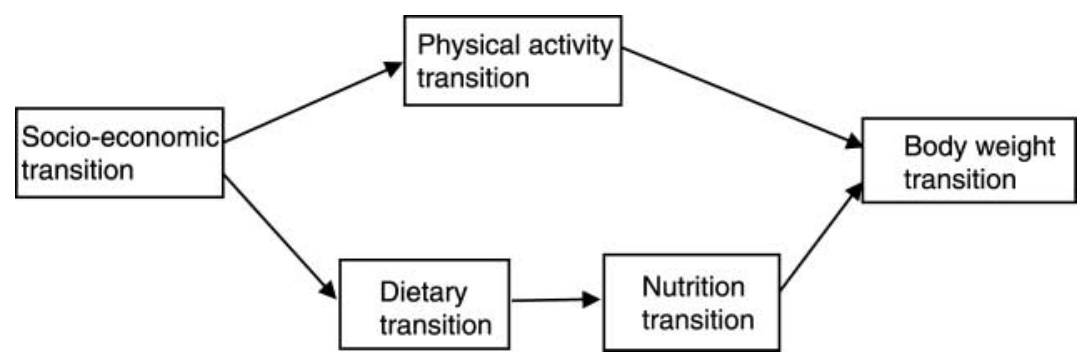

Fig. 1 A system of relationships between transitions

of movement also changes, from walking to mass transportation to driving a car, which decreases total expenditure from physical activity ${ }^{14,15}$.

Dietary transitions involve shifts in the foods consumed in a society ${ }^{7,16}$. Dietary behaviours are an important part of social structure and social processes, and as societies change diets also change. Dietary transitions are closely correlated with income level ${ }^{17-19}$. The major aspect of the dietary transition occurs as diets are delocalised ${ }^{20}$, and fewer locally produced plant foods and more imported and processed animal foods are consumed. Another aspect of the dietary transition is uncoupling of food preparation from food consumption $^{21}$. Traditionally, foods were consumed by whom and where they were prepared. However, as women who are the traditional food handlers increasingly enter the paid labour force, food consumption outside the home such as take-out foods, eating out and fast foods increases $^{14,21,22}$. Dietary transitions have also been propelled by technological advances in food processing and packaging ${ }^{7}$.

Nutrition transitions occur as economic changes transform the food system of a society to provide a different mix of nutrients ${ }^{11,23-29}$. As societies change from traditional to industrialised, the proportions of macronutrients consumed change to include more protein, more fat and less carbohydrates $^{30}$. Micronutrient consumption is also affected; while nutrient deficiency tends to disappear with economic development, fibre consumption tends to decline. These nutritional changes reflect dietary transitions. Higher consumption of processed foods may result in lower micronutrient consumption, but it may also increase micronutrient consumption if the processed foods are fortified. Increased consumption of animal foods may lead to higher protein and fat consumption.

Body weight transitions involve shifts in the overall level of body fat of people in a society ${ }^{13}$. In traditional societies, individuals are often undernourished and rarely obese, while in industrialised societies people are often obese and less often thin ${ }^{13}$. Body weight transitions occur as a part of societal changes that influence diet and physical activity. As societies pass through the socio-economic, physical activity, dietary and nutrition transitions, social conditions facilitate weight gain ${ }^{14}$ and the desire for a thin body ${ }^{13}$.
South Korea is a nation that has undergone considerable social change during the last few decades, and the patterns of South Korean social, nutritional and health changes have been especially striking. The proposed model of development as a system of transitions is examined empirically in the present paper using South Korea as an example. Examining how this system of transitions occurs on a national level in one country that has recently undergone rapid economic development may provide an example of how such transitions may operate in other nations.

\section{Methods}

\section{Sample}

The sample for this analysis is national data available for the years between 1969 and 1993 in South Korea. The initial year of 1969 was chosen because the Korean National Nutrition Survey started that year, and several variables in this study were extracted from that survey. The ending year of 1993 was selected because classification of occupation was changed as of 1994, making comparison with subsequent years impossible. These 24 years are a time when considerable social changes occurred in South Korean society.

\section{Measures}

National population-level data are available as a series of indicators of socio-economic, physical activity, dietary, nutrition and body weight transitions. All of the data came from published South Korean government reports. Most of the data used in this study are also available at South Korean government websites (www.korea.net and www.nso.go.kr).

Three indicators of socio-economic transitions included gross national product (GNP), percentage of the population that is urban and percentage of high school graduates. The GNP indicates the goods and services produced by a country as a whole, and has been used as an indicator of development of a national economy ${ }^{8}$. The percentage of urban population shows how much urbanisation has occurred. The percentage of high school graduates reflects the development of human capital through education. GNP and percentage of urban population were obtained from the Korean Statistical 
Yearbook ${ }^{31}$ and the percentage of high school graduates was taken from Social Indicators in Korea $^{32}$. Data on percentage of urban population were available every five years until 1988 and yearly after that, and the percentage of high school graduates was available every five years.

Physical activity transitions for the nation as a whole were assessed using three related indicators. The annual proportion of the population involved in primary (agricultural), secondary (manufacturing) and tertiary (service) industries was calculated. Industrial activity reflects the amount of energy expenditure at work, ranging from the heavy physical work involved in farm production to the sedentary activity of office work ${ }^{7,11}$. The South Korean government used six employment categories: (1) professional, technical, administrational and managerial workers; (2) clerical and related workers; (3) sales workers; (4) service workers; (5) agriculture-, forestry- and fishery-related workers; and (6) production, transportation, equipment operation and labours. The first four categories were collapsed to represent tertiary industries. Although they are different types of industry, the amount of physical activity involved in these industries is similar, compared with the other industries. The proportion of the population involved in agriculture-, forestry- and fishery-related work was used to represent primary industry. The proportion of the population involved in production, transportation, equipment operation and labour was used to represent secondary industry. This information was obtained from the Korean Statistical Yearbook ${ }^{31}$.

The number of cars and the number of driver's licences were also used to reflect modes of people's daily movement, with driving indicating less physical activity than walking, bicycling or using mass transportation. This information was taken from the Statistical Yearbook of Transportation ${ }^{33}$.

Dietary transitions were measured using two groups of indicators. The first group included the Engel Index and eating-out expenditure. The Engel Index is the percentage of income spent on food that is purchased from sources outside the home such as markets and restaurants, and has an inverse relationship with economic development ${ }^{34}$. Eating-out expenditure indicates the proportion of income used to consume food outside the household. South Korea national averages for the Engel Index and eating-out expenditure were not available; however, separate averages for urban and rural areas were available. Engel Index and eating-out expenditure for rural areas are available from 1976 onwards, while those for urban areas from 1969 onwards were found in Social Indicators in Korea $^{32}$

The second group of dietary transition indicators consisted of proportions of energy, protein and fat supplied from animal and plant foods, and energy consumption from cereals. Energy from cereal grains is important because rice is a staple in the South Korean $\operatorname{diet}^{35}$. Energy, protein and fat consumptions from animal and plant foods were taken from the Food Balance Sheets $^{36}$. Data on fat consumption from 1969 to 1974 are not available. Energy consumption from cereal grains was taken from the Korean National Nutrition Survey Reports ${ }^{37,38}$. The Korean National Nutrition Survey Report is an annual survey of households that assesses a variety of nutritional parameters of household members and reports annual aggregate data for the nation as a whole.

Nutrition transitions were measured by aggregated data on how much energy was contributed to people's intake from carbohydrates, protein and fat. These data were obtained from the Korean National Nutrition Survey Reports $^{37}$.

Body weight transitions were assessed using average body mass index (BMI) of adolescents at the age of 17 years. Height and weight of adolescents in high schools are measured annually and aggregated height and weight for each age are reported in the Statistical Yearbook of Education $^{39}$. From those heights and weights, BMI was calculated using the relationship: weight (in $\mathrm{kg}$ ) divided by the square of height (in $\mathrm{m}$ ). BMI is used widely in nutritional epidemiology as a population-based measure of the amount of body fat and level of obesity ${ }^{40}$, including studies on adolescents ${ }^{41}$.

\section{Analysis}

The time series data from each of the indicators were first examined by year for each of the transitions to describe patterns in the data over time. The theoretical model presented in Fig. 1 was examined with path analysis using the CALIS procedure in SAS software ${ }^{42}$. One indicator from each transition was selected by examining correlations among the multiple indicators within each type of transition. For the socio-economic transition, GNP was the only variable for which values were available for all years. The proportion of tertiary industry was chosen for the physical activity transition because it was highly correlated ( $r=0.82$ to 0.98 ) with other indicators and carries theoretical significance of work-related physical activity. Percentage energy from cereal grains was used to represent the dietary transition because of its high correlation ( $r=0.87$ to 0.92$)$ with other indicators and its substantive importance as a representation of starchy staples intake ${ }^{18,30}$. Percentage energy from fat represented the nutrition transition for the same reasons. The body weight transition was represented by the average BMI of 17-year-old males and females. Log transformation was performed on GNP to normalise the distribution to produce better path models ${ }^{43}$.

\section{Results}

\section{Socio-economic transition}

South Korea proceeded rapidly through a socio-economic transition during the years examined here. The GNP of 
South Korea increased more than 50 -fold over the 24 years, from $\$ 66$ billion to $\$ 3308$ billion (Table 1). The proportion of the population living in urban areas also grew from $41.1 \%$ in 1970 to $76.3 \%$ in 1993 , while the percentage of the population with a high school diploma increased from $10 \%$ in 1970 to $33.5 \%$ in 1990 . GNP was very strongly related to urban population $(r=0.89, P<0.0001)$ and population with a high school diploma $(r=0.94$, $P<0.05)$.

\section{Physical activity transition}

In South Korea, physical activity decreased in job-related and transportation areas. The physical activity transition was assessed using two types of proxy variable. Proportions of the working population in industry sectors indicated physical activity at work. Over the years examined here, the number of people in the primary industry sector (agriculture, fishing and forestry) decreased significantly, while the number of people in the tertiary industry sector (service industries) reached more than half the working population in South Korea (Table 1). Therefore, physical activity from work appears to have decreased substantially at the national level. The proportion of the population in the primary industry sector was negatively associated with the proportions of the population in the secondary sector $(r=-0.95$, $P<0.001)$ and the tertiary sector $(r=-0.98$, $P<0.0001)$, while the secondary sector and the tertiary sector were positively associated $(r=0.86, P<0.0001)$.

The second type of proxy variable (number of passenger cars and number of driver's licences) for a physical activity transition examined the mode of people's transportation. The number of driver's licences started to go up from 1978 and increased steadily from then on, although the number of passenger cars did not increase substantially until the late 1980s (Table 1). During the 1980s, many South Koreans began to obtain a driver's licence even if they did not own a car at that time. It is assumed that public transportation was the major mode of movement for South Korean people until 1990, when more individuals began to own cars. The number of passenger cars and the number of driver's licences were highly correlated $(r=0.97, P<0.0001)$. The proportion of the population in the primary industry sector showed a consistent and significant negative relationship with the number of passenger cars $(r=-0.77, P<0.0001)$ and the number of driver's licences $(r=-0.89, P<0.0001)$, while the proportions of the population in the secondary and tertiary industry sectors showed a significant positive relationship $(r=0.86, P<0.001)$.

\section{Dietary transition}

South Koreans' diets changed substantially over this period. The Engel Index fell significantly from the late 1970 s for both urban and rural areas, from $46.9 \%$ to $29.6 \%$ and from $45.7 \%$ to $21.9 \%$, respectively (Table 1 ).
The income urban and rural households spent on foods consumed outside the home grew from less than $1 \%$ to approximately $8 \%$ for urban residents and $4 \%$ for rural residents. This away-from-home spending increase for food started in the late 1980s. The Engel Index in urban areas was positively related to the Engel Index in rural areas $(r=0.98, P<0.0001)$, while the Engel Index in both urban and rural areas was negatively related to the percentage of income urban and rural households spent on foods away from home $(r=-0.95, P<0.001$ and $r=-0.93, P<0.001$, respectively).

The supply of animal foods increased, while the supply of plant foods decreased (Table 1). The energy supplied from animal foods was about 5\% in 1970 and increased threefold over the 24 years. The energy supplied from plant foods decreased from $95 \%$ to $86 \%$. Energy consumed from cereal grains decreased more substantially, from $86 \%$ to $64 \%$. Therefore, over the period studied, South Koreans consumed more animal foods and less plant foods, while the dependency on cereals as a staple source of energy decreased drastically. The percentage of energy supplied from plant foods was negatively associated with the percentage of energy supplied from animal foods $(r=-1.00, P<0.0001)$ and positively associated with the percentage of energy supplied from cereal grains ( $r=0.91, P<0.0001$ ).

More protein and fat were consumed from both animal and plant foods. Total protein consumption per capita per day increased steadily over the years, and the increase was primarily from animal protein. Total protein consumption was positively related to the percentage of protein supplied from plant foods $(r=0.72, P<0.001)$ and the percentage of protein supplied from animal foods $(r=0.99, P<0.001)$. By contrast, the rising consumption of fat from plant oils appears to have contributed substantially to the increasing total fat consumption. While plant fat consumption increased almost fourfold, animal fat consumption increased about only twofold. Total fat consumption was associated with the percentage of fat supplied from plant foods $(r=1.00, P<0.0001)$ and the percentage of fat supplied from animal foods $(r=0.95, P<0.0001)$.

All of these measures of dietary transitions were significantly related to each other (all $P<0.05$ ), with the Engel Index and the percentage of income spent on awayfrom-home foods showing the opposite direction of correlation to the other measures. Lower Engel Indexes were positively associated with higher energy consumption from animal foods and higher protein and fat consumption from both plant and animal foods.

\section{Nutrition transition}

The dietary transition led to the nutrition transition, represented by increased energy from protein and fat and decreased energy from carbohydrates (Table 1). In 1969, Koreans acquired $80 \%$ of their energy consumption from 
Transitions in South Korea

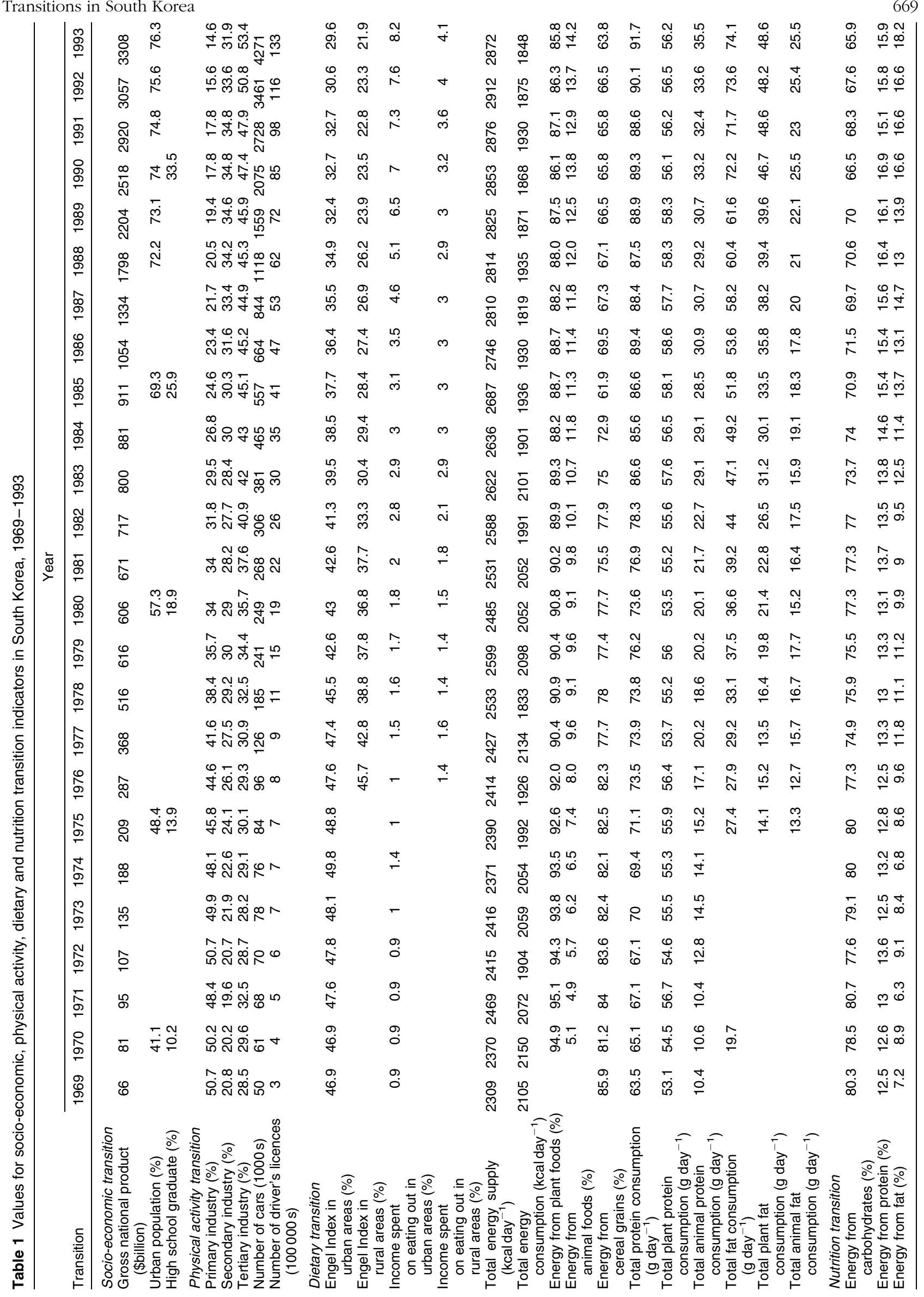


carbohydrates, while approximately $66 \%$ of energy came from carbohydrates in 1993. Percentage energy from fat showed the opposite pattern. Fat provided more than twice as much energy to South Koreans in 1993 (18.2\%) than in 1969 (7.2\%). Interestingly, percentage energy from protein did not change as much as percentage energy from fat. Protein provided 13\% of daily energy in 1969 and 16\% in 1993. Most changes in the nutrition transition occurred in carbohydrate and fat intakes. While percentage energy from carbohydrate was negatively related to percentage energy from both protein $(r=-0.92, P<0.0001)$ and fat $(r=-0.98, P<0.0001)$, the percentage energy from protein and fat were positively related to each other $(r=0.85, P<0.0001)$.

\section{Body weight transition}

The average BMI of 17-year-old adolescents increased steadily over this time period (Fig. 2). Girls showed less of an increase in average BMI than boys. Changes in the average BMIs of girls and boys were significantly correlated $(r=0.86, P<0.0001)$.

\section{Relationships among transitions}

Results of the path analysis are presented for each gender in Figs 3 and 4. Path analysis showed a relatively good fit of the model to the data. The model with 17-year-old boys (Fig. 3) revealed standardised residuals less than 0.05, a normed fit index (NFI) of 0.92, a comparative fit index (CFI) of 0.94 and a significant chi-square test $\left(\chi^{2}=17.22\right.$, $P=0.004)$. These indicators of standardised residuals, NFI, CFI and chi-square are used to assess the goodnessof-fit of the tested models. Since models are not considered a good fit if standardised residuals are greater than 1, NFI and CFI are less than 0.9, and there is a nonsignificant chi-square test ${ }^{42}$, the model with 17 -year-old boys appeared to be a good fit by meeting three out of four criteria. All path coefficients in the model with 17-year-old boys were significant at $P=0.001$. The model with 17-year-old girls (Fig. 4) also showed a relatively good fit, with standardised residuals less than 0.5 , NFI $=0.89$, $\mathrm{CFI}=0.92$ and a significant chi-square test $\left(\chi^{2}=17.95\right.$, $P=0.003)$. In the model with 17 -year-old girls, the path coefficient (0.08) leading from the nutrition transition to the weight transition was not significant at $P=0.05$ $(t=0.3843)$.

Standardised path coefficients showed that GNP had a strong influence on the proportion of tertiary industry and the percentage energy from cereals. Percentage energy from cereals was inversely related with percentage energy from fat. Average BMI of 17-year-old boys had path coefficients of 0.54 with proportion of tertiary industry and 0.46 with percentage energy from fat. Average BMI of 17-year-old girls had a higher path coefficient (0.68) with proportion of tertiary industry and a lower path coefficient (0.08) with percentage energy from fat. It should be noted that the weight transition in 17-year-old girls had the highest residual of 0.67 compared with other transitions.

\section{Discussion}

As South Korea went through rapid economic development, there were significant changes in the physical activity, diet, nutrition and body weight of the population. South Koreans have used less energy in job-related activity and transportation over time. Simultaneously, their diet has incorporated more animal foods and plant oils. Increased consumption of plant oils was largely responsible for a higher proportion of energy coming from fat. The relative body weights of adolescents showed a steady increase.

Separation of food consumption from food preparation occurred in South Korea, as shown by increasing expenditures on eating out. This trend was displayed more dramatically in the growth of the South Korean fast food and convenience food industries ${ }^{44}$. Until the late

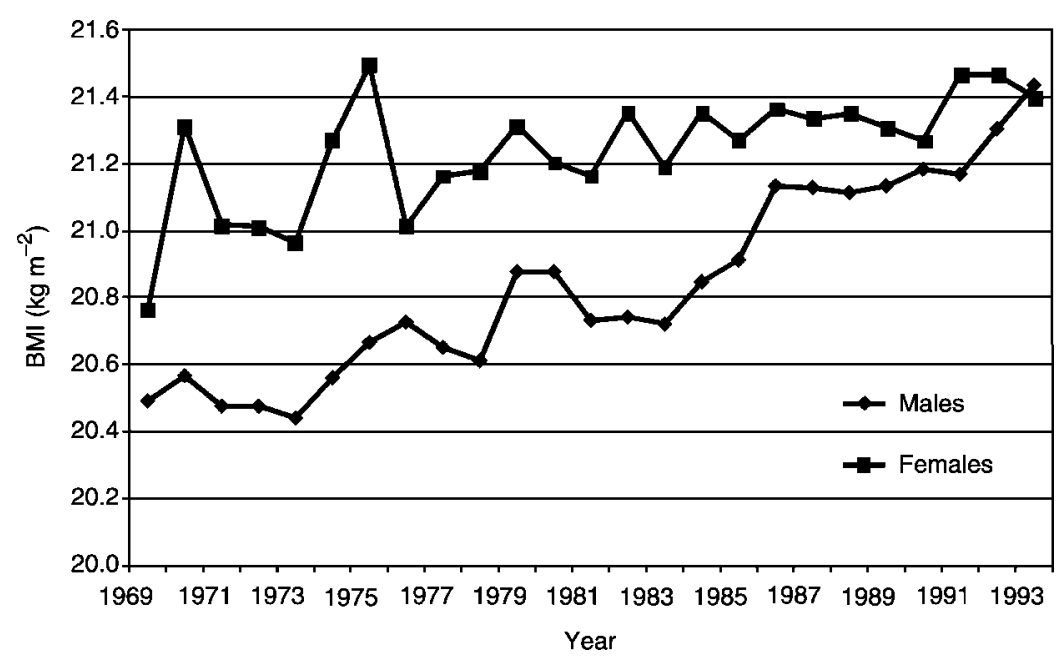

Fig. 2 Weight transition: changes in body mass index (BMI) of 17-year-old adolescents 


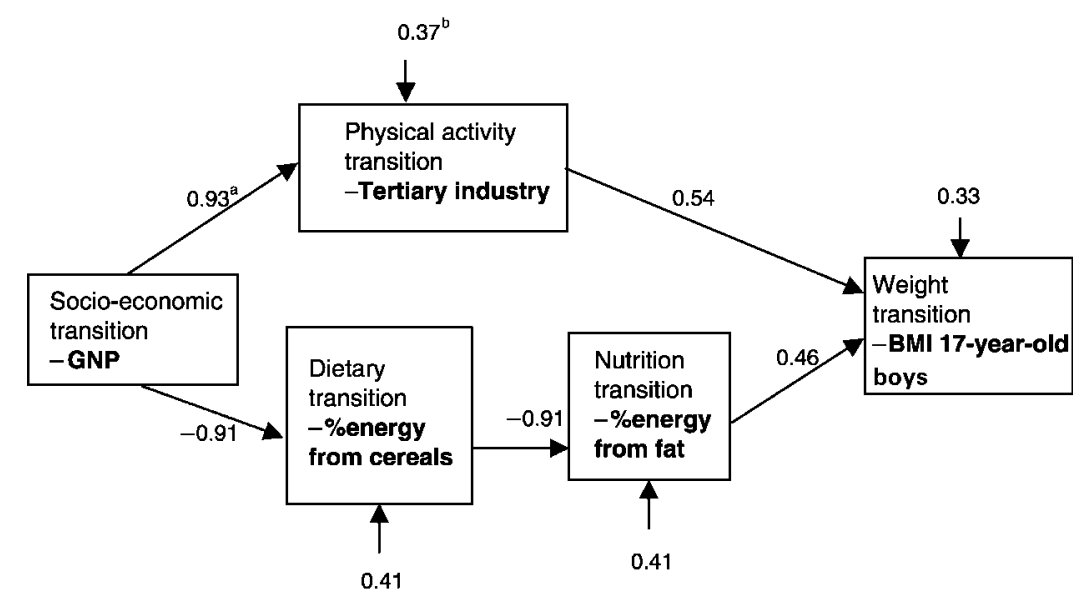

a. Numbers on the arrows between transition boxes are path coefficients

b. Numbers on the outside arrows pointing into transition boxes are residuals

Fig. 3 A model of a system of transitions in the average body mass index (BMI) of 17-year-old boys (GNP - gross national product)

1970s, many households made their own Korean soybean paste that is essential in Korean cuisine, but now nearly every household purchases Korean soybean paste from markets. This trend also occurred in other essential ingredients of Korean cuisine, including the staple vegetable dish kimchi. Increasing food imports have created anxiety in South Korea, such as the crisis over possible foot-and-mouth disease from imported beef and the high lead content of seafood imported from China ${ }^{45}$.

Changes in food items consumed in South Korea were substantial. Rice has been a vital staple for Koreans throughout history. The decline in percentage energy from cereal grains, from 86\% in 1969 to 64\% in 1993, showed that South Koreans have begun to consume more of other food items. While plant foods still provided more than $80 \%$ of food energy in 1993 , the percentage energy from animal foods almost tripled during the years examined here $(5 \%$ to $14 \%)$. This increase in animal food consumption contributed significantly to both protein and fat intakes. Since consumption of total plant protein virtually did not change over the time period, the increase of total protein consumption resulted from animal food consumption. However, the dramatic increase in fat intake, while relatively low compared with other countries, was clearly propelled by plant fat consumption. The increase in plant fat consumption was almost twice that of animal fat consumption. Contribution of plantbased foods to fat intake was reported in a study that used a total food duplicate method ${ }^{46}$. The importance of fat from plant sources has also been demonstrated in other countries $^{30}$.

What is not clear is whether and how dietary transitions were associated with total energy consumption. Korea Food Balance Sheets reported that total energy supply per capita increased from $2309 \mathrm{kcal}$ in 1969 to $2872 \mathrm{kcal}$ in 1993; however, the Korean National Nutrition Survey

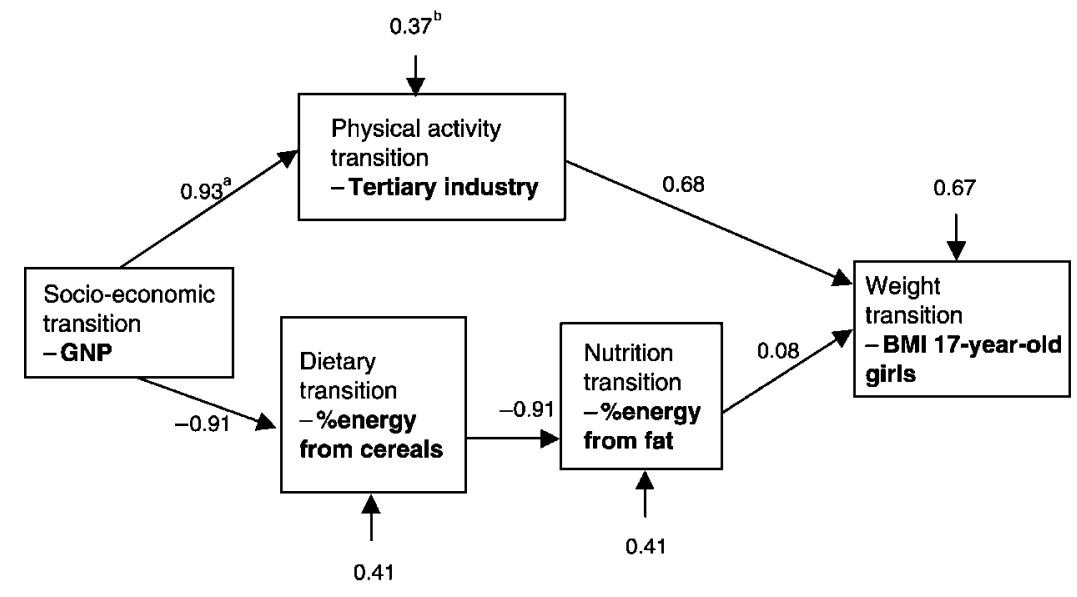

a. Numbers on the arrows between transition boxes are path coefficients

b. Numbers on the outside arrows pointing into transition boxes are residuals

Fig. 4 A model of a system of transitions in the average body mass index (BMI) of 17-year-old girls (GNP - gross national product) 
Reports showed that actual energy consumption by individuals declined from $2105 \mathrm{kcal}$ in 1969 to $1848 \mathrm{kcal}$ in 1993. The Korean population has matured ${ }^{47}$, with an increasing median age of the population ( 18.5 years in 1970 to 27 years in 1990) and a decreasing proportion of individuals younger than 14 years ( $41 \%$ in 1969 to $24 \%$ in 1993). Individuals over 65 years old accounted for only $3 \%$ (1969) to 5\% (1993) of the total population. Therefore, this discrepancy seems to show that South Koreans consumed less energy with different macronutrient profiles over the years in an increasingly food-abundant environment. Since the Korean National Nutrition Surveys used a direct weighing measuring method for assessing household food consumption, underreporting of dietary intake affected by changing social norms emphasising low body weight is not a valid explanation for these dietary changes. This pattern needs to be explored further in relation to body weight transitions on both the individual and the national level.

A body weight transition occurred in South Korea and was predicted by other transitions. The path models showed that the coefficients of the path from the activity transition to the body weight transition were somewhat higher than the coefficients of the path from the nutrition transition to the body weight transition in both adolescent boys and adolescent girls. This finding should be evaluated in the light of other considerations. For example, total caloric consumption, and not only dietary fat, is important in relation to body weight ${ }^{48}$, and caloric intake was not controlled for this analysis. This analysis also did not address the social pressure for girls to be thin, which leads girls to participate in purposeful weight control and diets ${ }^{49}$. This social pressure is significantly associated with economic development, and may be mediating the relationship between the nutrition transition and the body weight transition. This is supported by the finding that girls had a higher residual (0.67) than did boys (0.33) in the path model, meaning the proposed model explained the body weight transition of boys better than girls. Inappropriate weight control or dieting is an area that needs much attention from public health nutritionists in relation to obesity.

Changes in each transition described here have been reported in other Asian countries ${ }^{50-53}$. As countries achieve economic development, people seem to consume more animal food-based and high-fat diets and to engage in less physical labour. Lee et al. ${ }^{54}$ reported that South Korea uniquely has a relatively low prevalence of obesity and a lower level of total dietary fat compared with other Asian countries. Recently, South Korea has witnessed much interest in body weight management across all ages and genders, as well as dramatic growth in the weight loss industry especially targeting women. Combined with a finding of this study that the average BMI changed more among boys than girls, this suggests that it may be possible that South Korea will reverse its course in body weight transition, at least among women, as Japan has ${ }^{55}$. Analysis of a body weight transition over 20 years (1976-1995) in Japan showed that while the average BMI increased by half a unit each year among men, the average BMI actually decreased - albeit slightly - each year among women ${ }^{55}$.

This study was limited by using aggregated data on the national level, although it used time series data. Use of correlations and path analysis for time series data has several limitations. Some of the high correlations may be due to use of aggregated data ${ }^{56}$. This study inherited the shortcomings of the methods used in data collection. Food balance sheets can only provide food supply data, not actual food consumption of individuals. The Korean National Nutrition Survey provided information about food consumption; however, it has its own limitations including the use of household-based food assessment methods ${ }^{57}$. The survey utilised the direct food weighing method on the household level because South Koreans share all foods at the same table. The nutrient information calculated from the weighted food information was then divided into each individual's share in the household, using specific conversion factors based on age and sex. While this method may not provide accurate food consumption data on the individual level, it may provide more meaningful food consumption data on the population level. This study was also limited by indirect indicators for transitions, such as use of employment structure and the number of cars for representing the physical activity transition. These indirect indicators may not provide information about the actual amount of physical activity, however they can provide valuable social indicators of activity on the population level. This study was not able to include recreational physical activity because there were no national data available. However, since recreational physical activity tends to become significant with greater economic development, it would be important to examine this transition in future analysis. Perhaps the most important data that were not available are the proportions of individuals who were overweight and obese. This information would have been able to more completely represent the extent of the body weight transition.

In future research, two types of datasets would be ideal for studying how transitions are interrelated each other: longitudinal data on individuals in a country that experienced rapid socio-economic development and longitudinal aggregated data from many countries in different stages of socio-economic development. However, most developing countries did not begin their health and nutrition surveillance early enough to permit adequate historical comparisons. In turn, valid and comparable longitudinal aggregated data from many countries in different stages of socio-economic development are also not available for extensive multinational comparisons.

The finding that a body weight transition was associated with both physical activity and nutrition transitions 
indicated that it is important to think about the issue of the trend of increasing obesity using wider and more systematic approaches. The trend of increasing obesity cannot be changed only by educating individuals about eating and exercise; what is also required is to deal with the way societies facilitate healthy food consumption and physical activity $^{14,58}$.

\section{References}

1 Beaver SE. Demographic Transition Theory Reinterpreted. Lexington, MA: Lexington Books, 1975.

2 Zelensky W. The hypothesis of the mobility transition. Geographical Review 1971; 61(1): 219-49.

3 Omran AR. The epidemiologic transition: a theory of the epidemiology of population change. Milbank Memorial Fund Quarterly 1971; 49: 509-38.

4 Omran AR. Epidemiologic transition in the United States: the health factor in population change. Population Bulletin 1977; 32(2): 2-42.

5 Omran AR. Epidemiologic transition. In: Ross JA, ed. International Encyclopedia of Population. New York: Free Press, 1982; 172-5.

6 Harrison D. The Sociology of Modernization and Development. Boston, MA: Unwin Hyman, 1988.

7 Sobal J. Food system globalization, eating transformations, and nutrition transitions. In: Grew R, ed. Food in Global History. Boulder, CO: Westview Press, 1999; 171-93.

8 Case KE, Fair RC. Principles of Economics, 3rd ed. Englewood Cliffs, NJ: Prentice Hall, Inc., 1994.

9 Popkin BM. Urbanization, lifestyle changes and the nutrition transition. World Development 1999; 27: 1905-16

10 Popkin BM, Bisgrove EZ. Urbanization and nutrition in low income countries. Food and Nutrition Bulletin 1988; 10: $3-23$.

11 Popkin BM, Paeratakul S, Zhai F, Ge K. Dietary and environmental correlates of obesity in a population study in China. Obesity Research 1995; 3: 135S-43S.

12 Prentice AM, Jebb SA. Obesity in Britain: gluttony or sloth?. British Medical Journal 1995; 311: 437-9.

13 Sobal J. Social and cultural influences on obesity. In: Bjorntorp P, ed. International Textbook of Obesity. Chichester: John Wiley and Sons, 2001; 305-22.

14 French SA, Story M, Jeffery RW. Environmental influences on eating and physical activity. Annual Review of Public Health 2001; 22: 309-35.

15 Hill JO, Peters JC. Environmental contributions to the obesity epidemic. Science 1998; 280: 1371-4.

16 Grigg D. The nutrition transition in Western Europe. Journal of Historical Geography 1995; 21(3): 247-61.

17 Bennett MK. International contrasts in food consumption. Geographical Review 1941; 31: 365-76.

18 Bennett MK. The World's Food: A Study of the Interrelations of World Population, National Diets, and Food Potentials. New York: Harper, 1954.

19 Food and Agriculture Organization (FAO). Income Effect on the Structure of Diet: Provisional Indicative World Plan for Agricultural Development. Rome: FAO, 1973; 2: 500-5.

20 Pelto GH, Pelto PJ. Diet and delocalization: dietary change since 1975. In: Rothberg RI, Rabb TK, eds. Hunger and History: The Impact of Changing Food Production and Consumption Patterns on Society. Cambridge: Cambridge University Press, 1983; 309-30.

21 Burns C, Jackson M, Gibbons C, Stoney RM. Foods prepared outside the home: association with selected nutrients and body mass index in adult Australians. Public Health Nutrition 2002; 5: 441-8.
22 Warde A, Martens L. Eating Out: Social Differentiation, Consumption, and Pleasure. New York: Cambridge University Press, 2000.

23 Kim S, Moon S, Popkin BM. The nutrition transition in South Korea. American Journal of Clinical Nutrition 2000; 71 : $44-53$.

24 Monteiro CA, Mondini L, de Souza AL, Popkin BM. The nutrition transition in Brazil. European Journal of Clinical Nutrition 1995; 46: 105-13.

25 Popkin BM. Nutritional patterns and transitions. Population and Development Review 1993; 19: 138-57.

26 Popkin BM. The nutrition transition in low income countries: an emerging crisis. Nutrition Reviews 1994; 52: 285-98.

27 Popkin BM. The nutrition transition and its health implications in lower income countries. Public Health Nutrition 1998; 1: 1-21.

28 Popkin BM. The shift in stages of the nutrition transition in the developing world differs from past experiences. Public Health Nutrition 2002; 5: 205-14.

29 Popkin BM, Ge K, Zhai F, Guo X, Ma H, Zohoori N. The nutrition transition in China: a cross-sectional analysis. European Journal of Clinical Nutrition 1993; 47: 333-46.

30 Drewnowski A, Popkin BM. The nutrition transition: new trends in the global diet. Nutrition Reviews 1997; 55: 31-43.

31 National Statistical Office. Korean Statistical Yearbook. Seoul: Government Printing, 1971-1995 [in Korean].

32 National Statistical Office. Social Indicators in Korea. Seoul: Government Printing, 1971-1997 [in Korean].

33 Ministry of Construction and Transportation. Statistical Yearbook of Transportation. Seoul: Government Printing, 1973-1993 [in Korean].

34 Senauer B, Asp E, Kinsey J. Food Trends and the Changing Consumer. St. Paul, MN: Eagan Press, 1991.

35 Lee SK, Sobal J, Frongillo EA. Acculturation and dietary practices among Korean Americans. Journal of the American Dietetic Association 1999; 99: 1084-9.

36 Korean Rural Economics Institute. Food Balance Sheet. Seoul: Government Printing, 1971-1993 [in Korean].

37 Ministry of Health and Social Affairs. National Nutrition Survey Report. Seoul: Government Printing, 1972-1995 [in Korean].

38 Ministry of Health and Social Affairs. Yearbook of Health and Social Statistics. Seoul: Government Printing, 1971-1993 [in Korean].

39 Ministry of Education. Statistical Yearbook of Education. Seoul: Government Printing, 1970-1994 [in Korean].

40 Willett W. Nutritional Epidemiology, 2nd ed. New York: Oxford University Press, 1998.

41 Gordon-Larsen P, Adair LS, Popkin BM. The relationship of ethnicity, socioeconomic factors, and overweight in US adolescents. Obesity Research 2003; 11: 121-9.

42 Hatcher L. A Step-by-Step Approach to Using the SAS System for Factor Analysis and Structural Equation Modeling. Cary, NC: SAS Institute Inc., 1994

43 Kleinbaum DG, Kupper LL, Muller KE. Applied Regression Analysis and Other Multivariable Methods. Belmont, CA: Duxbury Press, 1988.

44 Mo S. The culture of eating out adds nutritional problems. Journal of the Korean Medical Association 1990; 33: 27-31 [in Korean].

45 Hangeyre Newspaper. High lead content in imported seafood from China. 26 November 2001 [in Korean].

46 Moon CS, Zhang ZW, Imai Y, Shimbo S, Watanabe T, Moon $\mathrm{DH}$, et al. Nutrition evaluation of women in urban and rural areas in Korea as studied by the total food duplicate method. Tohoku Journal of Experimental Medicine 1997; 181: 245-65 [in Japanese].

47 National Statistical Office. Footsteps of Korea through Statistics. Seoul: Government Printing, 1995 [in Korean].

48 Food and Nutrition Board, Institute of Medicine. Dietary 
Reference Intakes for Energy, Carbohydrate, Fiber, Fat, Fatty Acids, Cholesterol, Protein, and Amino Acids (Macronutrients). Washington, DC: National Academy Press, 2002.

49 Cash TF, Roy RE. Pounds of flesh. In: Sobal J, Maurer D, eds Interpreting Weight: The Social Management of Fatness and Thinness. New York: Aldine De Gruyter, 1999.

50 Kosulwat V. The nutrition and health transition in Thailand. Public Health Nutrition 2002; 5: 183-9.

51 Shetty PS. Nutrition transition in India. Public Health Nutrition 2002; 5: 175-82.

52 Du S, Lu B, Zhai F, Popkin BM. A new stage of the nutrition transition in China. Public Health Nutrition 2002; 5: 169-74.

53 Noor MI. The nutrition and health transition in Malaysia. Public Health Nutrition 2002; 5: 191-5.

54 Lee MJ, Popkin BM, Kim S. The unique aspects of the nutrition transition in South Korea: the retention of healthful elements in their traditional diet. Public Health Nutrition 2002; 5: 197-203.

55 Yoshiike N, Seino F, Tajima S, Arai Y, Kawano M, Furuhata T, et al. Twenty-year changes in the prevalence of overweight in Japanese adults: the National Nutrition Survey 1976-1995. Obesity Reviews 2002; 3: 183-90.

56 Morgenstern H. Ecologic studies in epidemiology: concepts, principles, and methods. Annual Review of Public Health 1995; 16: 61-81.

57 Moon HK. The method of the Korean National Nutrition Survey. Korean Journal of Nutrition 1994; 27: 509-24 [in Korean].

58 Campbell TC, Chen J, Brun T, Parpira B, Qu Y, Chen C, et al. China: from diseases of poverty to diseases of affluence. Policy implications of the epidemiological transition. Ecology of Food and Nutrition 1992; 27: 133-44. 